\title{
Logística Reversa de Defensivos Agrícolas: fatores que influenciam na consciência ambiental de agricultores gaúchos e mineiros
}

\author{
Wagner Junior Ladeira ${ }^{1}$, Alisson Eduardo Maehler ${ }^{2} \mathrm{e}$ \\ Luís Felipe Machado do Nascimento ${ }^{3}$
}

Resumo: Nos últimos anos, observa-se um aumento das pressões legais e sociais em favor de uma maior preocupação com o meio ambiente em vários países, incluindo o Brasil. Se antes o foco era indústrias poluidoras, agora, também o setor agrícola sofre essas pressões. Considerando este cenário, o presente estudo tem como objetivo verificar quais são os principais fatores que levam produtores rurais a realizarem a logística reversa de embalagens de defensivos agrícolas. Para isso, foram aplicados questionários a 398 agricultores (residentes no Rio Grande do Sul e em Minas Gerais), produtores de soja, café, fumo, feijão e morango. Analisaram-se tanto as questões ambientais quanto as questões legais incluídas nesse processo. A fim de se atingir o objetivo proposto, foi adotada uma abordagem quantitativa, através da análise de regressão múltipla. No modelo de regressão estimado, observou-se que, dentro do processo de recolhimento de embalagens, três questões foram relacionadas à consciência ambiental: i) manuseio de defensivos agrícolas e a legislação atual; ii) adoção de tecnologia e de novas práticas e iii) riscos a saúde humana. Nos achados empíricos a consciência ambiental recebe fortes interferências de fatores relacionados ao manuseio de defensivos agrícolas e da legislação atual.

Palavras-chaves: logística reversa, meio ambiente, defensivos agrícolas.

Abstract: In recent years, legal and social pressures in favor of environmental affairs have increased in several countries, including Brazil. If, before, concerns were mainly focused on large polluting companies, nowadays, the agricultural sector is also influenced by this matter. Considering this scenario, this study aims to identify which are the main factors that lead rural producers to perform the milk run process. In order to evaluate this process, questionnaires were sent to 398 farmers (residents in Rio Grande do Sul and Minas Gerais States), producers of soybean, coffee, tobacco, beans and strawberry. We analyzed both environmental and legal issues. In order to achieve the objective proposed, a quantitative

1 Doutor em Administração pela UFRGS. Professor da Unisinos. E-mail: wjladeira@ea.ufrgs.br

2 Doutor em Administração pela UFRGS. Professor Adjunto da UFPel. E-mail: alisson.maehler@gmail.com

3 Doutor em Economia e Meio Ambiente pela Universität Gesamthochschule Kassel, Alemanha. Professor Associado da UFRGS. E-mail: nascimento@ea.ufrgs.br 
approach was adopted, using multiple regression analysis. In the regression model estimated, it was observed that, in the process of collecting packaging, three questions were related to environmental awareness: i) handling pesticides and current legislation, ii) adoption of new technology and practices, and iii) risks to human health. Empirical findings in environmental awareness receive strong interference of factors relating to the handling of pesticides and current legislation.

Key-words: reverse logistics, environment, pesticides.

Classificação JEL: Q5.

\section{Introdução}

O discurso das práticas ambientais corretas tem assumido um papel relevante na sociedade atual. Algumas questões têm recebido atenção crescente a respeito de seu impacto, além de enfrentar pressões da sociedade e do governo para melhorar seu desempenho (UNNIKRISHNAN e HEGDE, 2007). A redução do uso de recursos e a política de produtos sustentáveis tornaram-se o discurso comum nas sociedades industriais modernas e nos esforços ambientais de muitas organizações (LOGOZAR et al., 2006).

$\mathrm{Na}$ tentativa de incentivar a consciência ambiental, órgãos públicos criam leis e estabelecem condutas com o intuito de preservar o meio ambiente e a qualidade de vida da população. $\mathrm{O}$ governo federal, por exemplo, criou, no final da década de 90, uma série de medidas que tentam reduzir as agressões ao meio ambiente. Uma dessas diz respeito à devolução dos vasilhames (já utilizados) de produtos tóxicos empregados nas lavouras. Em 1989 foi editada a Lei n. 7.802, de 11 de julho, a qual regulamenta a pesquisa, a experimentação, a produção, a embalagem, a rotulagem, o transporte, o armazenamento, a comercialização, a propaganda comercial, a utilização, a importação, a exportação, o destino final dos resíduos e embalagens, bem como o registro, a classificação, o controle, a inspeção e a fiscalização de defensivos agrícolas (BRASIL, 2008).

Ainda nesse sentido, tal conjunto de medidas e leis repassa a responsabilidade do produto final e seu descarte ao agricultor e à empresa produtora de defensivos agrícolas. No caso do recolhimento das embalagens de defensivos agrícolas utilizadas nas plantações, a cooperação depende diretamente dos produtores rurais, que fazem parte de um elo da cadeia agrícola, como destacado por Inpev (2010). A cooperação existente entre os elos da cadeia agrícola pode ser observada pelos fluxos de entrega ou logística convencional (matéria-prima, manufatura, distribuição e varejo) e pelos fluxos de recolhimento ou logística reversa (coleta, transporte, desmantelamento e decomposição).

A Lei n. 7.802 representou um avanço na proteção ambiental, pois definiu o conceito de defensivos agrícolas, estabeleceu as características necessárias para as embalagens e escolheu quais informações deveriam aparecer nos rótulos. Em 2000, a Lei n. 9.974 (BRASIL, 2008a) regulamentou a obrigatoriedade do recolhimento e destinação final das embalagens após o uso dos defensivos agrícolas, pelas empresas que produzem e pelas que comercializam os defensivos agrícolas.

A aprovação dessas leis foi resultado do aumento da consciência ambiental da população e da pressão exercida por ONGs ambientalistas. Apesar de abrangerem todo o território nacional, percebeu-se que, em alguns estados, tais leis foram implantadas com maior eficiência do que em outros. Quais seriam, portanto, os motivos para que isso tenha ocorrido? Que fatores mais contribuíram para a devolução das embalagens: a força da lei ou a conscientização dos agricultores? Existem diferenças significativas na devolução das embalagens de defensivos agrícolas entre as culturas de fumo, soja, feijão, café e morangos? Dentro deste conjunto de questionamento, o 
presente estudo tem como objetivo verificar quais são os principais fatores que levam os produtores rurais a realizarem a logística reversa de embalagens de defensivos agrícolas.

Para se alcançar o objetivo proposto, o artigo estrutura-se em seis seções. Esta primeira seção apresenta a introdução, ao passo que, na segunda, são apresentadas as questões da responsabilidade e consciência ambiental na sociedade moderna, bem como as questões legais envolvidas no processo de recolhimento de embalagens. A terceira seção, por sua vez, aborda os aspectos metodológicos, ao demonstrar como foi definida a amostra e selecionado o método para análise. $\mathrm{Na}$ quarta seção é realizada a interpretação dos dados. Na quinta seção discutem-se comparativamente os achados empíricos com a base teórica utilizada. Por fim, a sexta seção apresenta as considerações finais e indicações de estudos futuros.

\section{Fundamentação teórica}

Para que se compreenda melhor o objetivo de estudo deste trabalho, sua base teórica é constituída de três partes, tendo como proposta de análise a consciência ambiental através de três perspectivas: i) Manuseio de defensivos agrícolas e a legislação atual; ii) adoção de tecnologia e novas práticas e iii) Riscos à saúde humana.

A Figura 1 a seguir apresenta uma síntese da estruturação teórica utilizada.

\subsection{Consciência ambiental}

A crescente inquietação da comunidade global em relação à qualidade de vida e a sobrevivência do meio ambiente natural é um dos temas mais debatidos neste início de século XXI (EGRI e PINFIELD, 1998). Segundo Leal (2003), a ciência administrativa tem recebido grandes incentivos para estudar as perspectivas ecológicas. Segundo a autora, longe de ser um modismo gerencial, a perspectiva ecológica tem se mostrado predominante em alguns estudos de casos administrativos.

A busca da sustentabilidade ambiental tem sido evidenciada nos últimos anos pela limitação do consumo de recursos facilmente esgotáveis; pelas políticas de redução dos resíduos e pela busca de meios de conservação e reciclagem de energia e de recursos (SACHS, 1993). As atividades econômicas, em especial de setores industriais altamente poluidores, podem impactar negativa

Figura 1. Estruturação da base teórica.

Estruturação da Base Teórica
Manuseio de defensivos agrícolas e legislação atual
Realização da tríplice lavagem das embalagens de defensivos agrícolas
Inutilização das embalagens de defensivos agrícolas
Armazenamento das embalagens de defensivos agrícolas
Recebimento de informações de manuseio por parte das empresas vendedoras
Recebimento de informações de manuseio por parte das cooperativas


e significativamente o ambiente natural, reduzindo a biodiversidade, lançando gases de $\mathrm{CO}_{2}$ na camada de ozônio, afetando a qualidade das águas, entre outros.

A responsabilidade da comunidade com os danos ambientais cresceu muito nas últimas décadas, mas foi ao longo dos anos 70 que começaram a emergir os primeiros conceitos com relação à seguridade ambiental, nos quais o meio ambiente passou a ser uma preocupação constante em agendas políticas (LEAL, 2003). O crescimento da consciência ambiental levou as indústrias e (também) a agricultura a buscarem novas formas de redução do impacto de suas atividades no meio ambiente e a modificar suas práticas.

A inserção de legislação específica (decreto de Lei n. 7.801/1989), que obriga as empresas distribuidoras a realizarem um recolhimento adequado e destinação das embalagens de defensivos agrícolas, por um lado, e um aumento na consciência ambiental dos agricultores, por outro, tem melhorado os índices de recolhimento de embalagens no Brasil. Desse modo, argumenta-se que o recolhimento de embalagens vazias de defensivos agrícolas pode ser considerado um ato de consciência ambiental por parte do produtor rural. Nesse sentido, diversos fatores podem estar relacionados, em maior ou menor grau, ao recolhimento de tais embalagens.

\subsubsection{O recolhimento das embalagens de defensivos agrícolas e a legislação atual}

Os negócios na agricultura estão sob a influência da desregulamentação do mercado, do comércio livre e da globalização (DOGLIOTTI, ITTERSUM e ROSSING, 2006; BARBIER, 2006), aliados às práticas mais sustentáveis e ecológicas de produção (SHI e GILL, 2005; MARSDEN e SMITH, 2005; KASSAHUN, 2006). Nos últimos anos, muitas empresas têm dado mais ênfase às questões ambientais não apenas como diferencial competitivo, mas também como questão de responsabilidade para com o meio ambiente e as gerações futuras. Nesse ponto, a área de gestão tem sido influenciada por conceitos que trazem o foco para os impactos ambientais (DOBERS e WOLFF, 1999; SHARMA e HENRIQUES, 2005; MARCHAND E WALKER, 2008).

A busca pela agricultura sustentável é um objetivo importante sob o ponto de vista do planejamento econômico e do desenvolvimento do planeta (XU et al., 2006). Oerlemans (2004) menciona que os produtores rurais podem utilizar meios eficazes que contribuam para o desenvolvimento de uma agricultura mais sustentável. No entanto, o que se observa é a falta de dados ou informações empíricas nessa temática (BRUCKMEIER e TOVEY, 2008).

Questõescomoa responsabilidadeambiental, a utilização e o manuseio de defensivos agrícolas e as consequências do uso excessivo de produtos químicos têm se popularizado no discurso dos proprietários rurais. Como já mencionado, várias são as legislações que estabelecem padrões para o uso e manuseio de tais defensivos. A Associação Nacional dos Distribuidores de Insumos e Agrícolas Veterinários - Andav (2011), por exemplo, destaca as seguintes legislações: o Decreto n. 4.074, de 04 de janeiro de 2002, que regulamenta a Lei n. 7.802, de 11 de julho de 1989, a qual dispõe sobre os aspectos que vão da pesquisa ao controle, inspeção e fiscalização de defensivos agrícolas, seus componentes e afins, e a Resolução n. 334, de 03 de abril de 2003, que dispõe sobre os procedimentos de licenciamento ambiental de estabelecimentos destinados ao recebimento de embalagens vazias de defensivos.

Nos primeiros seis meses de 2008, o Brasil teve em suas unidades de recebimento de embalagens de defensivos agrícolas, 12 mil toneladas de recipientes. Esse volume representa um crescimento de 9,8\% em relação ao mesmo período do ano anterior, quando foram destinadas 10,9 mil toneladas (INPEV, 2008). De acordo com o Instituto Nacional de Processamento de Embalagens Vazias - Inpev (2008), no Brasil existem hoje, entre postos e centrais, cerca de 380 unidades de recebimento de embalagens. Esses dados representam um avanço em termos 
de consciência ecológica no meio rural, mas ainda são insuficientes para recolher todas as embalagens comercializadas. Dado o avanço da fronteira agrícola e o consequente aumento da área plantada, tornar-se-á necessário ampliar rapidamente a estrutura de logística reversa para o recolhimento dessas embalagens. De modo resumido, o processo de logística reversa de recolhimento de embalagens de defensivos envolve quatro elementos (ou elos): a) o agricultor; b) os canais de distribuição; c) a indústria e d) o poder público (INPEV, 2010).

No que se refere ao agricultor, compete ao mesmo lavar as embalagens utilizadas (tríplice lavagem), inutilizá-las, armazená-las e entregá-las, além de comprovar a devolução, pois deve manter os comprovantes de entrega de embalagens e notas fiscais. No que se refere aos canais de distribuição, nomeadamente distribuidores e cooperativas, estas têm a missão de informar os produtores, disponibilizar e gerenciar o local de recebimento das embalagens, emitir o comprovante de entrega e orientar e conscientizar os agricultores.

Aindústria, porsuavez, segundoaInpev (2010), tem como tarefa recolher as embalagens vazias, efetuar a destinação final (por meio de reciclagem e incineração) e orientar e conscientizar o agricultor. Por fim, compete ao poder público a fiscalização, licenciamento das unidades de recebimento, educação e conscientização de produtores rurais. Além destes, também as cooperativas agrícolas possuem papel fundamental da conscientização dos produtores rurais.

Nesse sentido, dada a amplitude do processo de recolhimento de embalagens de defensivos agrícolas exigido por lei, a necessidade de integração entre os elos e seu caráter holístico, espera-se que:

a) A realização de tríplice lavagem das embalagens de defensivos pelo produtor rural esteja relacionada à devolução (das mesmas) às empresas fornecedoras;

b) A inutilização das embalagens de defensivos esteja relacionada à devolução (das mesmas) às empresas fornecedoras; c) O armazenamento das embalagens de defensivos esteja relacionado à devolução (das mesmas) às empresas fornecedoras;

d) O recebimento de informações de manuseio por parte das empresas vendedoras esteja relacionado à devolução de embalagens de defensivos agrícolas às empresas fornecedoras; e

e) O recebimento de informações de manuseio por parte de cooperativas esteja relacionado à devolução de embalagens de defensivos agrícolas às empresas fornecedoras.

\subsubsection{A adoção de tecnologia e de novas práticas na agricultura}

Os avanços na agricultura nos últimos anos permitiram um incremento de produtividade em diversas culturas e países, como o Brasil, conforme dados da Circular Técnica 59 da Embrapa (EMBRAPA, 2008a). Muitos desses avanços se deram em virtude da utilização de novas tecnologias e de novas técnicas de cultivo, como a adoção do método de plantio direto na palha, a intensa mecanização agrícola, o uso de organismos geneticamente modificados (OGMs), o uso de fertilizantes e de defensivos, entre outros. Tais elementos têm permitido aumentar a produção nacional e a produtividade em um ritmo maior do que o aumento da área plantada, conforme dados do IBGE (2009).

Autores como Mendola (2007), que analisou pequenas propriedades rurais em Bangladesh, na Ásia, e Minten e Barrett (2008), com trabalho semelhante em Madagascar, na África, observam que a adoção de tecnologias agrícolas por agricultores cumpre um papel relevante em termos de redução da pobreza local, aumento da produtividade e redução dos riscos de quebra ou falhas na agricultura. Isso porque, além de aumentar a produtividade, permite aos agricultores armazenar a produção e comercializá-la no momento mais adequado.

Para a adoção de novas tecnologias é necessário, entretanto, que informações sejam disponibilizadas 
aos produtores, os quais deverão possuir qualificação técnica e profissional para absorvê-las.

Isso pode ser constatado no trabalho de Wolf (2008), na medida em que ele ressalta a profissionalização do produtor rural, aliada a uma visão de "empreendedor" ou "empresário" rural, e que exerce papel fundamental no desenvolvimento e crescimento tanto da propriedade quanto da região onde esse trabalhador está inserido.

Ainda segundo Wolf (2008), há a importância das redes sociais de trocas de ideias, para que haja a complementaridade de conhecimentos entre produtores rurais, além da atuação de agentes públicos, muitas vezes limitados em sua atuação. Ações tais como dias de campo, palestras, seminários e ações extensionistas proporcionam a obtenção de informações sobre os mais variados assuntos, entre eles o processo de recolhimento de embalagens de defensivos agrícolas. Espera-se, portanto, que:

a) A adoção de novas tecnologias utilizadas no campo esteja relacionada à devolução de embalagens de defensivos agrícolas às empresas fornecedoras;

b) A adoção de novas formas de manejo na lavoura esteja relacionada à devolução de embalagens de defensivos agrícolas às empresas fornecedoras;

c) A participação de produtores rurais em seminários que discutem o uso de defensivos agrícolas esteja relacionada à devolução de embalagens às empresas fornecedoras.

\subsubsection{Riscos à saúde humana}

Cada vezmais háum aumento da preocupação em relação às questões de saúde humana, como a ocorrência de problemas de saúde na família devido ao uso de defensivos agrícolas. O aumento da consciência ambiental por parte dos produtores rurais é mais um reflexo do aumento dessa preocupação humana. Segundo dados da Opas/OMS (1996), estima-se que, mundialmente, ocorram cerca de 3 milhões de intoxicações por ano em razão do uso de defensivos agrícolas, que ocasionam 220 mil óbitos, com maiores incidências em países em desenvolvimento.

No Brasil, segundo o Ministério da Saúde (2006), os dados oficiais brasileiros sobre intoxicações por defensivos agrícolas não retratam a realidade do país, pois os dados se mostram insuficientes, parciais, fragmentados, desarticulados e dispersos em várias fontes, segundo o próprio Ministério. Por uma série de razões, muitos agricultores não registram dados referentes à frequência de aplicação, dosagem e tempo de exposição, nem mesmo se submetem a consultas médicas ou tratamentos.

Mesmo que o agricultor tenha ciência dos possíveis riscos à saúde que o uso de defensivos oferece, isso não o impede, no entanto, de manipulá-los, apesar de haver um discurso generalizado de conciliação entre a busca de uma maior produtividade agrícola com a adoção de práticas ecológicas.

Espera-se, portanto, que:

a) A ocorrência de problemas de saúde na família (decorrentes do uso de defensivos agrícolas) esteja relacionada à devolução de embalagens vazias às empresas fornecedoras;

b) A busca constante pela diminuição no uso de defensivos agrícolas esteja relacionada à devolução de embalagens vazias às empresas fornecedoras;

c) Ter consciência dos riscos que a pulverização traz à saúde humana esteja relacionado à devolução de embalagens vazias às empresas fornecedoras;

d) Conciliação de uma maior produtividade com práticas ecológicas esteja relacionada à devolução de embalagens vazias às empresas fornecedoras.

\section{Metodologia}

Um método de pesquisa consiste em projetos formais que visam a obtenção de dados de forma empírica, sistemática e objetiva para a solução de problemas ou oportunidades específicas 
Figura 2. Estruturação do método de pesquisa.

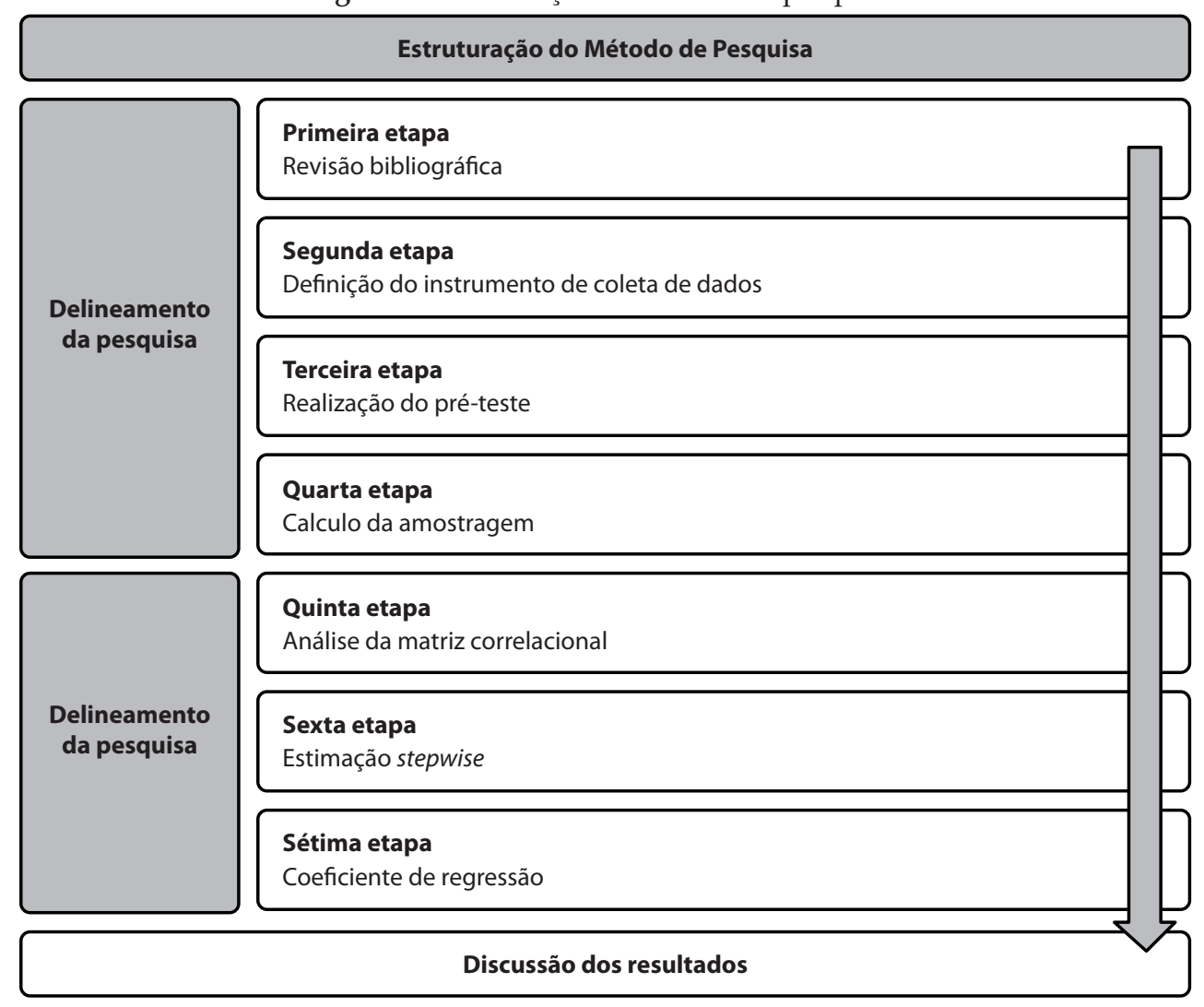

relacionadas (SAMARA e BARROS, 2002). Com base nessa visão, (DOWNING e CLARK, 1998; FREUND e SIMON, 2000), os dados foram coletados através de um questionário estruturado (KÖCHE, 2002; MARCONI e LAKATOS, 2005), e aplicou-se a análise de regressão múltipla (TABACHINICK e FIDELL, 2003; DANCEY e REIDY, 2006; HAIR et al., 1998; CUNHA e COELHO, 2007; MATOS, 2006) para alcançar o objetivo proposto.

A Figura 2 a seguir descreve o método utilizado e suas subdivisões.

\subsection{Delineamento da pesquisa}

$\mathrm{O}$ delineamento da pesquisa refere-se ao planejamento em sua dimensão mais ampla, o que envolve tanto a sua diagramação quanto a previsão de análise e interpretação dos dados (GIL, 1995). Quatro fases são essenciais no delineamento de uma pesquisa: a revisão bibliográfica, a definição do instrumento de coleta de dados, o pré-teste e a amostragem.

Em um primeiro momento, foram coletados referenciais bibliográficos para justificar a relação entre as variáveis independentes e a dependente. Logo após, optou-se por um questionário estruturado, como instrumento de coleta de dados. Esse questionário continha um total de cinco perguntas iniciais para a descrição da amostra - tipo de cultura cultivada; área em hectares plantados; tempo de exercício da atividade agrícola; localidade da propriedade rural e grau de escolaridade do responsável pela plantação. Formularam-se treze perguntas temáticas, às quais os entrevistados responderiam a partir de uma escala de um a cinco, em que o limite mínimo (um) representaria a discordância máxima, ao passo que o valor cinco representaria a concordância máxima. Os outros números receberam um valor gradativo, com opções em escala likert: (1) discordo amplamente, (2) 
discordo, (3) indiferente, (4) concordo e (5) concordo amplamente.

As treze perguntas foram analisadas; optou-se por identificar uma delas como a variável dependente $(\mathrm{Y})$ e as restantes, como independentes $(\mathrm{Xn})$. A variável dependente é aquela que o presente estude prevê: a devolução das embalagens vazias às empresas fornecedoras $(\mathrm{Y})$. As variáveis independentes são aquelas que preveem ou explicam a variável dependente, no caso em questão, as seguintes: inutilização das embalagens vazias de defensivos agrícolas (X1); adoção de novas tecnologias utilizadas no campo (X2); consciência dos riscos da pulverização à saúde humana (X3); disponibilização, pelas empresas vendedoras, de informações de manuseio (X4); armazenamento das embalagens vazias (X5); conciliação entre maior produtividade e práticas ecológicas (X6); ocorrência de problemas de saúde na família devido ao uso de defensivos agrícolas (X7); realização de tríplice lavagem das embalagens (X8); participação em seminários que discutam o uso de defensivos agrícolas (X9); busca constante pela diminuição no uso de defensivos agrícolas (X10); adoção de novas formas de manejo da lavoura $(X 11)$ e recebimento de informações de manuseio de cooperativas associadas (X12).

Logo após a estruturação do questionário, foi realizado um pré-teste com produtores rurais. Foram feitas entrevistas preliminares com cinco produtores. A intenção das entrevistas preliminares era verificar se o conteúdo dos questionários seria entendido pela amostra. Nessa entrevista, os produtores puderam projetar suas próprias concepções e valores a respeito do tema proposto, além de contribuir para o desenvolvimento do instrumento de coleta.

Realizados os pré-testes, deu-se início à coleta de dados através de amostragem. No caso da análise de regressão múltipla, as técnicas de cálculo de amostragem podem ser definidas através de sua significância, ao utilizar-se para o cálculo a fórmula $\mathrm{N} \geq 50+8 \mathrm{M}$ (DANCEY e REIDY, 2006). Em tal fórmula, o "N" representa o número de casos necessários dentro da amostra e " $\mathrm{M}$ ", o número de variáveis explicativas. Desse modo, o número de casos mínimos da amostra necessária para esta pesquisa seria 146, já que existem 12 variáveis independentes sob cálculo. Aconselha-se que haja 15 respondentes para cada variável independente (HAIR et al., 1998). Nesse caso, a amostra teria um mínimo de 180 questionários respondidos. Com base nessas duas indicações, a amostragem selecionou 400 casos, dos quais se esperava que alguns não fossem respondidos. No entanto, o retorno gerado na pesquisa foi de 398 questionários. Apenas dois questionários foram rejeitados por terem sido considerados outliers, ou seja, questionários que, por alguma razão, não puderam ser utilizados na pesquisa. A amostra foi composta por questionários aplicados nos estados do Rio Grande do Sul (61\%) e Minas Gerais (39\%). A escolha por esses estados ocorreu em função de ambos apresentarem um forte potencial agrícola e também pela facilidade de acesso dos pesquisadores aos pesquisados.

\subsection{Estimação do Modelo de Regressão}

As variáveis relevantes em uma pesquisa podem ser previstas de diversas formas (CUNHA e COELHO, 2007). Neste estudo, optou-se por uma integração entre duas técnicas que ajudam a explicar o relacionamento entre duas variáveis diferentes: correlação e análise de regressão múltipla. Ambas as técnicas compreendem a análise de dados amostrais para obter informações sobre a hipótese de duas ou mais variáveis serem relacionadas e qual a natureza desse relacionamento (HAIR et al., 1998).

A correlação visa a medir a força ou o grau de relacionamento entre variáveis. Já a técnica de regressão múltipla consiste em determinar uma função matemática que busca descrever o comportamento de determinada variável, denominada dependente, com base nos valores de uma ou mais variáveis, denominadas independentes (CUNHA e COELHO, 2007). A regressão múltipla indica os efeitos cumulativos de um grupo de variáveis explicativas $(X 1, X 2$, $\mathrm{X}$, etc.) em uma variável dependente (chamada 
de Y), assim como os efeitos separados dessas variáveis explicativas.

$$
\mathrm{Y}=\beta 1 \mathrm{X} 1+\beta 2 \mathrm{X} 2+\beta 3 \mathrm{X} 3+\ldots . .+\beta 0
$$

As análises de correlação e de regressão múltipla são técnicas comuns. No entanto, existem muitas maneiras de se conduzir uma regressão múltipla (TABACHINICK e FIDELL, 2003). Os passos descritos para análise neste trabalho estão divididos em três etapas.

Em um primeiro momento faz-se necessário analisar a matriz correlacional para evitar multicolinearidade. Essa etapa consiste em analisar a matriz correlacional, antes de seiniciaro processo de regressão múltipla. Seu objetivo é descobrir se algumas variáveis independentes estão altamente correlacionadas, o que evita a multicolinearidade. A multicolinearidade acontece quando se constatam variáveis que medem tipos de dados inter-relacionados, ou seja, variáveis que medem em grande quantidade o mesmo aspecto. Pode-se descobrir que tal fenômeno ocorre quando essas variáveis apresentam uma correlação acima de 0,8 (WOOLDRIGGE, 2006; DANCEY e REIDY, 2006; KMENTA, 1978).

Neste estudo, o grau de relacionamento entre as variáveis foi avaliado através do coeficiente momento-produto (ou $r$ de Pearson) e o fator de inflação da variância (FIV). O propósito deste coeficiente $r$ de Pearson é descobrir se existe relacionamento entre as variáveis. Para Hair et al. (1998), é importante utilizar certas estratégias, quando um estudo contém variáveis fortemente inter-relacionadas. Já a análise do FIV é adequada à avaliação dos coeficientes de correlação que são estimados em regressões auxiliares, ou seja, regredir cada $X_{i}$ sobre as demais variáveis explicativas $X$, obtendo-se, assim, os coeficientes de determinação $\left(R_{i}^{2}\right)$ de cada uma dessas regressões, que são objetos de análise.

Outra etapa importante é a estimação stepwise, que é um método de seleção de variáveis para inclusão no modelo de regressão e inicia-se com a seleção do melhor preditor da variável dependente. Nesse caso, as variáveis independentes adicionais são selecionadas em termos do poder explicativo incremental que podem acrescentar ao modelo de regressão (HAIR et al., 2001; WOOLDRIGGE, 2006). O modelo de regressão stepwise fornece uma sólida avaliação do problema de pesquisa, pois apresenta em diversos modelos os valores de $\mathrm{R}$ e $R^{2}$ (GUAJARATI, 2000). Cabe ao pesquisador escolher o modelo que melhor forneça uma explicação da variável dependente.

Por fim, sugerem-se o cálculo do coeficiente de regressão e a interpretação da variável de regressão. $\mathrm{O}$ modelo de regressão ajuda a identificar o coeficiente de regressão que avalia a importância relativa das variáveis individuais na previsão geral. Nessa etapa, a fim de se constatar a presença (ou não) de heterocedasticidade, foi utilizado o teste de White (HAIR et al., 1998; GUAJARATI, 2000); para verificar a hipótese de inexistência de erros de especificação do modelo final, foi utilizado o regression specification erros test (RESET) (SOARES e CASTELAR, 2003).

\section{Resultados e discussão}

Como foi descrito na revisão da literatura, existem fatores que estimulam os produtores rurais a realizar a devolução das embalagens utilizadas de defensivos agrícolas. Para melhor explicitar os resultados obtidos, este capítulo foi dividido em três partes, como segue: i) Estatística descritiva das variáveis; ii) Análise do modelo estimado e iii) Discussão dos resultados.

\subsection{Análise descritiva dos dados}

A amostra coletada é composta em sua totalidade por indivíduos do sexo masculino, os quais apresentam como grau de escolaridade marcante o ensino fundamental completo, totalizando 258 indivíduos $(71,6 \%)$. Na amostra, o tempo que os entrevistados vem exercendo a atividade agrícola é de em média de 17 anos, e o tamanho médio da área plantada em que trabalham foi de 12 hectares, considerada pequena propriedade. As principais culturas analisadas foram: fumo (36\%), soja (17\%), feijão $(16 \%)$, café $(15 \%)$, morango $(11 \%)$ e outros $(5 \%)$. 
Como já foi mencionado, a amostra contém questionários aplicados nos estados do Rio Grande do Sul (61\%) e Minas Gerais (39\%). Já que as amostras foram coletadas em lugares diferentes, esperava-se encontrar um viés de erro nas respostas, principalmente ao se relacionar estado e tamanho médio da propriedade. No entanto, não se pode considerar que existe uma diferença significativa na relação entre estados e tamanho médio da propriedade, pois, através do teste Qui-quadrado, foi comprovado que se deve aceitar a hipótese nula (Ho), devido a esse índice ser maior que 0,05. Com relação à escolaridade dos respondentes, foi comprovado que não existe correlação significativa com o estado da propriedade rural, pois foi aceita a hipótese nula (Ho), devido a esse índice também ser maior que 0,05 .

\subsection{Análise do modelo estimado}

A aplicação apropriada de um procedimento estatístico para cálculo de um modelo de regressão múltiplo, em um primeiro momento, deve investigar o pressuposto da multicolinearidade. Para investigar esse pressuposto, a presente pesquisa estimou a matriz correlacional ao inter-relacionar as 12 variáveis independentes e a variável dependente. Nessa matriz, encontram-se os valores do coeficiente momento-produto (ou $r$ de Karl Pearson) associados às 78 combinações possíveis (vide Quadro 1).
Ao se focalizar apenas as relações existentes entre as variáveis independentes, observa-se não haver aproximação da multicolinearidade. Somente as variáveis X1 (inutilização das embalagens vazias de defensivos agrícolas) e X5 (armazenagem das embalagens vazias) tiveram um coeficiente $r$ moderadamente forte de 0,756. No entanto, tecnicamente, essa correlação não tende a distorcer os coeficientes angulares estimados, muito menos a habilidade preditiva do modelo. Isso se dá, pois, segundo Dancey e Reidy (2006), o $r$ de Pearson deve ter valor superior a 0,8 para prejudicar a compreensão do real efeito da variável independente sobre o comportamento da variável dependente.

Nas relações entre variáveis independentes, nota-se ainda que há uma relação entre as variáveis: X8 (realização de tríplice lavagem das embalagens) e X12 (recebimento de informações de manuseio de cooperativas associadas), com um $r$ de 0,300; X1 (inutilização das embalagens vazias de defensivos agrícolas) e X8 (realização de tríplice lavagem das embalagens), com um $r$ de 0,274 . Apesar de tais variáveis independentes tenderem a um relacionamento positivo, seu coeficiente é classificado como fraco e não interfere diretamente na predição do modelo de regressão. No relacionamento entre a variável dependente (Y) e as variáveis independentes $(\mathrm{Xn})$, os coeficientes $r$ tiveram um bom nível de aceitação. $O$ relacionamento que teve maior coeficiente $(0,630)$

Quadro 1. Matriz correlacional.

\begin{tabular}{|c|c|c|c|c|c|c|c|c|c|c|c|c|}
\hline & $X_{1}$ & $X_{2}$ & $X_{3}$ & $X_{4}$ & $X_{5}$ & $X_{6}$ & $X_{7}$ & $X_{8}$ & $X_{9}$ & $\mathrm{X}_{10}$ & $X_{11}$ & $X_{12}$ \\
\hline$X_{1}$ & 1,000 & & & & & & & & & & & \\
\hline$X_{2}$ &,- 077 & 1,000 & & & & & & & & & & \\
\hline$X_{3}$ &,- 076 &,- 004 & 1,000 & & & & & & & & & \\
\hline $\mathrm{X}_{4}$ &,- 036 &, 012 &,- 029 & 1,000 & & & & & & & & \\
\hline $\mathrm{X}_{5}$ & ,756 &,- 133 &,- 099 &,- 003 & 1,000 & & & & & & & \\
\hline$X_{6}$ &,- 067 & 101 &,- 085 & 151 & ,004 & 1,000 & & & & & & \\
\hline$X_{7}$ & ,029 &,- 064 &,- 070 & ,087 & ,078 &,- 005 & 1,000 & & & & & \\
\hline $\mathrm{X}_{8}$ & ,274 & ,013 &,- 048 & ,072 & ,214 & ,118 &,- 061 & 1,000 & & & & \\
\hline$X_{9}$ & ,155 & ,209 &, 012 & 117 & ,049 & ,164 & ,059 & ,015 & 1,000 & & & \\
\hline$X_{10}$ & ,122 & 164 &, 034 &,- 004 & ,076 & ,143 &,- 002 &, 065 & ,141 & 1,000 & & \\
\hline$X_{11}$ & ,116 &,- 008 & ,079 & ,086 & 104 & 129 & 145 &, 087 &, 245 & ,204 & 1,000 & \\
\hline$X_{12}$ & 198 & ,061 &,- 048 & ,067 & ,109 &, 068 &,- 014 & ,300 & ,154 & ,157 & ,016 & 1,000 \\
\hline $\mathrm{Y}$ & ,630 & ,006 &,- 015 & 255 & ,547 &,- 050 &,- 020 &,- 144 & 139 & ,081 & ,053 & 186 \\
\hline
\end{tabular}

Fonte: Resultados da pesquisa. 
foi aquele vinculado à variável X1 (inutilização das embalagens vazias de defensivos agrícolas). Após isso, obteve-se o $r$ da variável X5 (armazenagem das embalagens vazias), com o valor de 0,547 . Esses dois relacionamentos mostraram-se moderadamente fortes, o que é bom sinal na predição de um modelo. Nessa etapa, observou-se que é preciso ter cautela com as variáveis $\mathrm{X} 3$ (consciência dos riscos da pulverização à saúde humana), X6 (conciliação entre maior produtividade e práticas ecológicas), X7 (ocorrência de problemas de saúde na família devido ao uso de defensivos agrícolas) e X8 (realização de tríplice lavagem das embalagens). Isso se deve ao fato de tais variáveis demonstrarem uma possível heterocedasticidade no modelo geral, que se expressa com a omissão de variáveis explicativas importantes, possivelmente pela existência na amostra de dados que extrapolam a realidade do fenômeno estudado.

A análise da multicolinearidade é uma questão de grau e não de natureza, pois sempre existirá correlação entre as variáveis independentes, devendo-se buscar as que apresentem em menor grau para minimizar dificuldades na interpretação de dados. A situação mais idealizada do modelo regressão é aquela que apresenta diversas variáveis independentes altamente correlacionados com a variável dependente, mas com pouca correlação entre elas próprias (CUNHA e COELHO, 2007).

Até o presente momento, os relacionamentos entre as variáveis estudadas demonstraram estar coerentes às aplicações de um modelo de regressão. Com o intuito de se estimar um modelo de regressão mais apropriado à realidade das variáveis, optou-se pela estimação stepwise (vide Quadro 2).
No quadro de estimação stepwise, foram originados cinco modelos. Dentro deles, as variáveis interligadas geraram cinco propostas de equações. Em um primeiro momento, a estimação stepwise indicou que as variáveis que vão da X6 ate a X12 estariam fora de um modelo de regressão, devido à sua baixa correlação com a variável dependente. Sobraram os relacionamentos entre as cinco primeiras variáveis independentes. No estudo, a baixa correlação significa que há a presença de variáveis espúrias, que não ajudam a explicar o modelo. Nesse caso, recomenda-se não adotá-las no modelo de regressão.

O primeiro modelo expressa a relação da variável dependente com a variável independente $\mathrm{X} 1$; o segundo adiciona a variável $\mathrm{X} 2$ ao primeiro modelo; o terceiro adiciona a variável $\mathrm{X} 3$ ao segundo modelo; o quarto adiciona a variável $\mathrm{X} 4$ ao terceiro modelo e o quinto adiciona a variável X5 ao quarto modelo.

Observou-se que, a cada adição de uma variável na tentativa de explicar a variável dependente, o $r$ e o $r$ ao quadrado (múltiplo ou de determinação) aumentaram progressivamente, até alcançar, respectivamente, os valores de 0,816 e 0,666 . Isso indica que o melhor modelo a ser adotado é o de número cinco, que contém as variáveis X1 (inutilização das embalagens vazias de defensivos agrícolas), X2 (adoção de novas tecnologias utilizadas no campo), X3 (consciência dos riscos da pulverização à saúde humana), X4 (recebimento de informações de manuseio das empresas vendedoras) e X5 (armazenagem das embalagens vazias), pois é o modelo que possui maior correlação entre variáveis independentes e a variável dependente.

Quadro 2. Definição do modelo através da estimação stepwise.

\begin{tabular}{|c|c|c|c|c|c|c|}
\hline Modelo & $\begin{array}{c}\text { Variável } \\
\text { dependente }\end{array}$ & $\begin{array}{c}\text { Variável } \\
\text { independente }\end{array}$ & R Múltiplo & R Quadrado & R Ajustado & $\begin{array}{c}\text { Erro padrão } \\
\text { da estimativa }\end{array}$ \\
\hline 1 & $\mathrm{Y}$ & $\mathrm{X}_{1}$ & 0,789 & 0,622 & 0,620 & 0,297 \\
\hline 2 & $\mathrm{Y}$ & $\mathrm{X}_{1}, \mathrm{X}_{2}$ & 0,799 & 0,638 & 0,634 & 0,291 \\
\hline 3 & $\mathrm{Y}$ & $\mathrm{X}_{1}, \mathrm{X}_{2}, \mathrm{X}_{3}$ & 0,805 & 0,649 & 0,644 & 0,287 \\
\hline 4 & $\mathrm{Y}$ & $\mathrm{X}_{1}, \mathrm{X}_{2}, \mathrm{X}_{3}, \mathrm{X}_{4}$ & 0,812 & 0,660 & 0,655 & 0,285 \\
\hline 5 & $\mathrm{Y}$ & $\mathrm{X}_{1}, \mathrm{X}_{2}, \mathrm{X}_{3}, \mathrm{X}_{4}, \mathrm{X}_{5}$ & 0,816 & 0,666 & 0,660 & 0,281 \\
\hline
\end{tabular}

Fonte: Resultados da pesquisa. 
No modelo 5, pode-se inferir que o R ajustado representa $66 \%$ das variações ocorridas na variável dependente, ou seja, esse valor indica o percentual de variação total de $Y$ (inutilização das embalagens vazias de defensivos agrícolas) explicado por X1, X2, X3, X4 e X5.

No Quadro 2, encontra-se ainda o erro padrão de estimativa, que é a raiz quadrada da soma dos quadrados dos erros dividida pelos graus de liberdade, o que representa a estimativa do desvio padrão dos valores reais dependentes em torno da reta de regressão. O erro do padrão da estimativa decresce gradativamente a cada modelo, do número um ao número cinco. Observa-se que, no modelo cinco, encontra-se o menor erro padrão da estimativa, o que evidencia o fato de tal modelo ser o melhor a ser adotado.

O quadro de resumo da ANOVA (análise da variância), de número 3 , demonstra que, juntas, as variáveis $\mathrm{X} 1, \mathrm{X} 2, \mathrm{X} 3, \mathrm{X} 4$ e $\mathrm{X} 5$ preveem a variável dependente $Y$. As chances de os resultados obtidos terem ocorrido por erro amostral são de somente 0,0001 . Isso demonstra que a significância é menor que 0,05, portanto, rejeita-se a hipótese de que o $r$ quadrado é igual a zero.

A soma total dos quadrados (57.989) é o resíduo quadrado que ocorreria se se utilizasse apenas a média da variável dependente para predição. Ao utilizar as variáveis independentes X1, X2, X3, X4 e X5, esse resíduo cai para 20.989. A previsão, no caso, não será perfeita, mas é melhor que a chance por si só $F(5,362)$ $=132.602$, com significância de 0,0001. $\mathrm{Na}$ estimação do modelo de regressão, a variação da variável explicada dar-se-á em proporção direta com a variação das variáveis independentes. Para estimação dessas variações, utilizou-se o Quadro 4, o qual descreve os pesos não padronizados (B) e padronizados $(\beta)$ para as variáveis $\mathrm{X} 1, \mathrm{X} 2, \mathrm{X} 3, \mathrm{X} 4$ e $\mathrm{X} 5$, junto aos valores $t$, de probabilidade, aos limites de confiança de $95 \%$ em torno de $\mathrm{B}$ e às estatísticas de colinearidade.

$O$ valor previsto para o intercepto, no caso, é $-1,42$, ao passo que os outros valores de B são associados diretamente a cada variável independente. No que tange à significância, todas se mostraram apropriadas, pois demonstraram um valor menor que 0,05. Com relação aos testes de colinearidade, todos se mostraram aceitáveis, pois os valores da tolerance ficaram entre 1 e 0,1, e da FIV, entre 1 e 10. Segundo Guajarati (2000), se forem mantidos esses valores, não haverá problemas de multicolinearidade no modelo. Abaixo segue a definição da equação de regressão múltipla.

Quadro 3. Resumo da ANOVA.

\begin{tabular}{|c|l|c|c|c|c|c|}
\hline \multirow{4}{*}{ Modelo 5 } & & Soma dos quadrados & df (gl) & Média dos quadrados & F & Sig. \\
\cline { 2 - 5 } & Regressão & 37.473 & 5 & 7,495 & \multirow{2}{*}{132,602} & \multirow{2}{*}{0,0001} \\
\cline { 2 - 5 } & Resíduos & 20.516 & 362 & 0,057 & & \\
\cline { 2 - 5 } & Total & 57.989 & 388 & & \\
\hline
\end{tabular}

Fonte: Resultados da pesquisa.

Quadro 4. Análise dos coeficientes.

\begin{tabular}{|c|c|c|c|c|c|c|c|c|c|}
\hline \multirow{3}{*}{ Modelo 5} & \multicolumn{3}{|c|}{ Coeficientes } & \multirow{3}{*}{$\mathbf{T}$} & \multirow{3}{*}{ Sig. } & \multicolumn{2}{|c|}{ Intervalo de confiança $\mathbf{9 5 \%}$} & \multicolumn{2}{|c|}{ Colinearidade } \\
\hline & \multicolumn{2}{|c|}{ Não param. } & \multirow{2}{*}{$\begin{array}{c}\text { Param. } \\
\text { B }\end{array}$} & & & \multirow{2}{*}{ Limite inferior } & \multirow{2}{*}{ Limite superior } & \multirow{2}{*}{ Tolerance } & \multirow{2}{*}{ FIV } \\
\hline & B & Erro padrão & & & & & & & \\
\hline Constante & $-1,42$ & 0,42 & & $-3,35$ & 0,01 & $-2,25$ & $-5,87$ & & \\
\hline$X_{1}$ & 0,71 & 0,11 & 0,44 & 7,01 & 0,0001 & 0,52 & 0,92 & 0,764 & 1,675 \\
\hline $\mathrm{X}_{2}$ & 0,11 & 0,03 & 0,11 & 2,63 & 0,009 & 0,03 & 0,16 & 0,891 & 1,562 \\
\hline$X_{3}$ & 0,12 & 0,57 & 0,08 & 2,07 & 0,039 & 0,01 & 0,23 & 0,452 & 1,591 \\
\hline $\mathrm{X}_{4}$ & 0,16 & 0,03 & 0,18 & 4,50 & 0,0001 & 0,09 & 0,23 & 0,923 & 1,002 \\
\hline$X_{5}$ & 0,31 & 0,09 & 0,23 & 3,53 & 0,001 & 0,14 & 0,49 & 0,967 & 1,078 \\
\hline
\end{tabular}


Quadro 5. Correção de heterocedasticidade de White.

\begin{tabular}{|c|c|c|c|c|c|c|c|c|}
\hline \multicolumn{4}{|c|}{ Incluindo as 398 observações } & \multicolumn{4}{c|}{ Correção de heterocedasticidade de White } \\
\hline Variáveis & Coeficiente & Erro-Padrão & $\mathbf{T}$ & Sig. & Coeficiente & Erro-Padrão & T & Sig. \\
\hline Constante & $-1,42$ & 0,42 & $-3,35$ & 0,01 & $-1,42$ & 0,18 & $-2,17$ & 0,02 \\
\hline$X_{1}$ & 0,71 & 0,11 & 7,01 & 0,0001 & 0,71 & 1,78 & 5,98 & 0,01 \\
\hline$X_{2}$ & 0,11 & 0,03 & 2,63 & 0,009 & 0,11 & 3,67 & 1,12 & 0,01 \\
\hline$X_{3}$ & 0,12 & 0,57 & 2,07 & 0,039 & 0,12 & 1,91 & 1,03 & 0,039 \\
\hline$X_{4}$ & 0,16 & 0,03 & 4,50 & 0,0001 & 0,16 & 0,87 & 3,41 & 0,01 \\
\hline$X_{5}$ & 0,31 & 0,09 & 3,53 & 0,001 & 0,31 & 2,82 & 0,87 & 0,01 \\
\hline
\end{tabular}

Fonte: Resultados da pesquisa.

$\mathrm{Y}=0,71 \mathrm{X} 1+0,11 \mathrm{X} 2+0,12 \mathrm{X} 3+0,16 \mathrm{X} 4+$ $0,31 \times 5-1,42$

Com o intuito de constatar a presença (ou não) de heterocedasticidade, pois este é um dos problemas comuns em estimação de modelos baseados em dados de seção cruzada, o que compromete a eficiência dos estimadores, foi utilizado o teste de White, que é realizado sobre os resíduos obtidos na estimativa dos MQO.

Ao se processar a correção de White, como se pode constatar no Quadro 5, observa-se que todas as estatísticas e estimativas apresentam-se iguais, a menos dos erros padrão e das estatísticas t. Como se observa, a coluna de erros apresenta valores elevados após a correção, reduzindo, assim, os valores de $t$, com exceção dos valores do intercepto, que são ajustados na direção contrária. Observa-se que, apesar da redução do teste $t$, os mesmos ainda são estaticamente diferentes de zero, ao nível de significância de $5 \%$ para todos os coeficientes, enquanto também não se alteram o poder explanatório do modelo e o teste de autocorreção dos resíduos.

Por fim, utilizou-se o regression specification erros test (RESET) para verificar a hipótese de inexistência de erros de especificação do modelo final. O RESET consiste no teste de um determinado modelo em relação a alternativas gerais não específicas, a qual verifica se o modelo estimado viola ou não a seguinte propriedade do MCRL (modelo clássico de regressão linear): $\sum \hat{u}_{i} \hat{y}_{i}=0$. Caso essa propriedade seja violada, indicará a existência de correlação serial entre os resíduos e a variável dependente estimada. Foram incluídas duas variáveis: X10 e X11. Essas duas variáveis não foram significativas ao percentual de $5 \%$, e o valor do coeficiente de determinação $\left(R^{2}=0,521\right)$ não foi significativamente maior do que o do modelo final. A estatística $F$ do teste RESET foi igual a 16,451 , a qual é menor que $(5,362)$ 132,602; não havendo motivo para rejeitar a hipótese nula de que o modelo não tem erros de especificação.

\subsection{Discussão dos resultados}

Analisada de uma maneira geral, a associação entre a variável dependente e as independentes é moderadamente forte ( $\mathrm{R}$ múltiplo 0,816 ). Juntas, as variáveis independentes representam $66 \%$ da variância. O coeficiente de regressão para X1 (inutilização das embalagens vazias de defensivos agrícolas) foi de 0,71 (com intervalo de confiança de $95 \%$, que varia de 0,52 a 0,92 ). O coeficiente de regressão para X2 (adoção de novas tecnologias utilizadas no campo) foi de 0,11 (com intervalo de confiança de $95 \%$, que varia de 0,03 a 0,16 ). $\mathrm{O}$ coeficiente de regressão para X3 (consciência dos riscos da pulverização à saúde humana) foi de 0,12 (com intervalo de confiança de $95 \%$, que varia de 0,01 a 0,23$)$.

Observa-se também que o coeficiente de regressão para X4 (recebimento de informações de manuseio das empresas vendedoras) foi de 0,16 (com intervalo de confiança de $95 \%$, que varia de 0,09 a 0,23). O coeficiente de regressão para X5 (armazenagem das embalagens vazias) foi de 0,31 (com intervalo de confiança de $95 \%$, que varia de 0,14 a 0,49 ). Como os intervalos 
de confiança não incluíram um valor negativo, é possível concluir que são positivos todos os coeficientes da regressão $(X 1: t=7,01 ; p=0,0001 /$ $X 2: t=2,63 ; p=0,0009 / X 3: t=2,07 ; p=0,0039 / X 4$ : $\mathrm{t}=4,50 ; \mathrm{p}=0,0001 / X 5: \mathrm{t}=3,53 ; \mathrm{p}=0,001)$.

Os coeficientes de regressão padronizados demonstram que a variável X1 (inutilização das embalagens vazias de defensivos agrícolas) é mais forte do que a restante. Todavia, ambas as variáveis estão positivas e significativamente relacionadas ao processo de inutilização das embalagens vazias de defensivos agrícolas.

No modelo de regressão estimado, observa-se que as principais variáveis influenciadoras da inutilização de vasilhames agrícolas são aquelas envolvidas com as questões legais. A variável que apresenta maior poder de explicação da devolução das embalagens vazias às empresas fornecedoras (Y) é a inutilização das embalagens vazias de defensivos agrícolas (X1), com um beta de 0,71 , ou seja: para cada variação de 1 para $Y, X 1$ tem a variação de 0,71 .

Logo após, tem-se a variável armazenamento das embalagens vazias (X5), que apresenta um beta de 0,31 , ou seja: para cada variação de 1 para Y, X5 tem a variação de 0,31 . A variável X5 é, na verdade, uma das etapas obrigatórias segundo a lei na inutilização dos vasilhames.

Com base nesses resultados obtidos, pode ser verificado que o manuseio de defensivos agrícolas e a legislação atual interferem na consciência ambiental, principalmente devido à inutilização e ao armazenamento das embalagens vazias. Além desses dois fatores, pode-se ainda citar o recebimento de informação com relação ao manuseio. Esses achados corroboram os argumentos de Xu et al. (2006), Oerlemans (2004) e Kassahun (2006), que sugerem em seus estudos que o manuseio de defensivos agrícolas e a legislação atual devem estar condicionados aos fatores que geram a consciência ambiental. Isso também demonstra que as várias legislações que ajudam a promover esse discurso - mencionadas pela Andav (2011) e Impev (2010) - influenciam os produtores rurais.
As outras variáveis, apesar de apresentarem um comportamento positivo, não chegaram a explicar o modelo com tanto poder de predição, tais como as variáveis X1 e X5. No entanto, as variáveis $X 1$ e $X 5$ demonstram que a adoção de tecnologia e de novas práticas e os riscos à saúde humana devem ser considerados como fatores que interferem na consciência ambiental. A inclusão de novas tecnologias utilizadas no campo (X2) enfatiza os argumentos mencionados por Mendola (2007), Wolf (2008) e Minten e Barrett (2008), os quais afirmam que pequenas propriedades rurais buscam a adoção de tecnologia a fim de aumentar ganhos econômicos e assumir um papel relevante em termos de redução da pobreza local. Já o fato de os produtores estarem cientes dos riscos da pulverização à saúde humana (X3) corrobora os achados do Ministério da Saúde (2006).

\section{Conclusões}

No presente artigo, buscou-se identificar quais fatores possuem maior poder de influência sobre a decisão de agricultores em retornar embalagens vazias de defensivos agrícolas, em um processo denominado logística reversa. De modo geral, vários fatores podem influenciar o agricultor a tomar essa decisão, em especial questões ligadas às pressões legais e a maior preocupação da sociedade com o meio ambiente e sua preservação, como mencionado.

No modelo estimado, não foram encontradas evidências da relação entre o manejo das embalagens de defensivos agrícolas e a preocupação ambiental. Os respondentes não fizeram uma relação direta entre o fato de manusearem embalagens e terem preocupação quanto aos impactos no meio ambiente ou na saúde humana. A questão ambiental nesta pesquisa demonstrou-se uma preocupação justificada pelas exigências da Lei n. 9.974, de 2000 (BRASIL, 2008). Os produtores rurais não se mostraram isentos das obrigações ambientais de manuseio das embalagens dos defensivos 
agrícolas; no entanto, as questões legais se mostraram mais relevantes. Isso demonstra que o aumento da consciência com as questões ambientais é impulsionado sobremaneira por aspectos legais.

Como o artigo argumenta que as pressões legais têm maior impacto sobre aspectos de logística reversa, um avanço nas leis ambientais, no que se refere à definição das obrigações entre agricultores e fornecedores, poderia apresentar um motivador adicional para o aumento do percentual de embalagens recolhidas, embora esses percentuais tenham se mostrado crescentes, segundo dados do Inpev (2010).

Por fim, sugere-se que mais estudos sobre recolhimento de embalagens de defensivos agrícolas sejam realizados, e abranjam tanto outras culturas quanto outros estados do País. Também podem ser pesquisadas as opiniões de fabricantes, comerciantes e distribuidoras de defensivos e outros insumos agrícolas. Já que o Brasil é um dos maiores produtores mundiais de alimentos, como soja, laranja, café e carne, entre outros (EMBRAPA, 2008), tais estudos se mostram relevantes e necessários.

O presente estudo fornece, além disso, um modelo aplicado a fatores que interferem no processo de devolução das embalagens utilizadas de defensivos agrícolas; unifica, dessa forma, o entendimento das relações funcionais acerca dos fatores relacionados à consciência ambiental nessa prática. Novas análises são estimuladas também com vistas à superação das limitações desta pesquisa. Entre tais limitações, podem ser citados o fato de a amostra não ser probabilística e o local de aplicação restringir-se aos estados do Rio Grande do Sul e de Minas Gerais. Investigações em outros estados e países permitiriam a comparação dos resultados em função das especificidades locais, bem como a incorporação de outras variáveis que poderiam representar um avanço na construção do modelo.

\section{Referências bibliográficas}

ANDAV - ASSOCIAÇÃO NACIONAL DOS DISTRIBUIDORES DE INSUMOS AGRÍCOLAS E VETERINÁRIOS. Legislação. Disponível na internet em $<\mathrm{http}$ ///www.andav.com.br/legislativo.aspx>. Acesso em: 17 jun. 2011.

BARBIER, E. B. Frontiers and sustainable economic development. Journal Enviromental and Resource Economics, v. 37, n.1, p. 271-295, 2007.

BRASIL. Decreto Lei no 7.802, de 11 de julho de 1989. Disponível na internet em <www.planalto.gov.br/ccicil > Acesso em: 15 jun. 2008.

BRASIL. Decreto Lei № 9.974, de 06 de junho de 2000. Disponível na internet em <www.planalto.gov.br/ ccicil>. Acesso em: 15 jun. 2008a.

BRUCKMEIER, K. e TOVEY, H. Knowledge in sustainable rural development: From forms of knowledge to knowledge processes. Sociologia Ruralis, v. 48, n. 3, p. 313-329, 2008.

CUNHA, J. V. A. da e COELHO, A. C. Regressão Múltipla. In: CORRAR, L. J., PAULO, E. e FILHO, J. M. D. (Coor.). Análise Multivariada. São Paulo: Atlas, p. 13123, 2007.

DANCEY, C. P. e REIDY, J. Estatística sem matemática para psicologia: usando SPSS para Windows. 4. ed. Porto Alegre: Artmed, 2006.

DOBERS, P. e WOLFF, R. Eco-efficiency and dematerialization: scenarios for new industrial logics in recycling industries, automobily and household appliances. Business Strategy and the Environmental, v. 8, n. 1 (Jan-Fev), p. 31-45, 1999.

DOGLIOTTI, S., ITTERSUM, M. K. e ROSSING, W. H. Influence of farm resource endowment on possibilities for sustainable development: A case study for vegetable farms in South Uruguay. Journal of Environmental Management, v. 78, n. 3, p. 305-315, 2006.

DOWNING, D. e CLARK, J. Estatística aplicada. São Paulo: Editora Saraiva, 1998.

EMBRAPA - EMPRESA BRASILEIRA DE PESQUISA AGROPECUÁRIA. Dados gerais. Disponível em: <www.embrapa.gov.br>. Acesso em: 10 set. 2008.

. Circular Técnica 59. Realidade e perspectiva do Brasil na produção de alimentos e agroenergia, com ênfase na soja. Londrina: EMBRAPA, setembro de 2008a. 
EGRI, C. P. e PINFIELD, L. T. As organizações e a biosfera: ecologia e meio ambiente. IN: CLEGG, S., HARDY, C. e NORD, D. (Orgs.). Handbook de Estudos Organizacionais. São Paulo: Atlas, v. 1, p. 363-399, 1998.

FREUND, J. e SIMON, G. Estatística aplicada: economia, administração e contabilidade. 9. ed. Porto Alegre: Bookman, 2000.

GIL, A. C. Métodos e técnicas de pesquisa social. 4. ed. São Paulo: Atlas, 1999.

GUAJARATI, D. Econometria básica. 3. ed. São Paulo: Makron Books, 2000.

HAIR JR, J. F. et al. Multivariate Data Analysis. 5. ed. Upper Saddle River: Prentice Hall, 1998.

IBGE - INSTITUTO BRASILEIRO DE GEOGRAFIA E ESTATÍSTICA. Censo Agropecuário 2006. Disponível em: <www.ibge.gov.br>. Acesso em: 20 jul. 2009.

INPEV - INSTITUTO NACIONAL DE PROCESSAMENTO DE EMBALAGENS VAZIAS. Estatísticas do setor. Disponível em: <www.inpev.org. br/educacao/noticias/br/noticias.asp > . Acesso em: 20 jun. 2008.

. Elos do sistema. Disponível em: <www.inpev. org.br/responsabilidades/elos_sistema $>$. Acesso em: 18 fev. 2010.

KASSAHUN, D. Towards the development of differential land taxation and its implications for sustainable land management. Environmental Science \& Policy, v. 9, n. 7-8, p. 693-697, 2006.

KMENTA, J. Elementos de Econometria. São Paulo: Atlas, 1978.

KÖCHE, J. C. Fundamentos de metodologia científica: teoria da ciência e iniciação à pesquisa. 20. ed. Rio de Janeiro: Vozes, 2002.

LEAL, M. E. De la R. Las ciencias administrativas y la sustentabilidad. Foro Nacional sobre La Incorporación de la Pespectiva Ambiental en la Formación Técnica y Profesional, 1, 2003, San Luis e Postosi. Anais... San Luis e Postosi: FNIPA, p. 01-10, 2003.

LOGOZAR, K., RADONJIC, G. e BASTIC, M. Incorporation of reverse logistics model into in-plant recycling process: A case of aluminium industry. Resources, Conservation and Recycling, v. 49, n. 1, p. 49-67, 2006.

MARCHAND, A. e WALKER, S. Product development and responsible consumption: designing alternatives for sustainable lifestyles. Journal of Cleaner Production, $\mathrm{v}$. 16, n. 11, p. 1163-1169, 2008.

MARCONI, M. de A. e LAKATOS, E. M. Fundamentos de metodologia científica. 6. ed. São Paulo: Atlas, 2005.
MARSDEN, T. K. e SMITH, E. Ecological Entrepreneurship: Sustainable Development in Local Communities Through Quality Food Production and Local Branding, Geoforum, n. 36, 2005, p. 440-445.

MATOS, O. C. de. Econometria básica: teoria e aplicações. 3. ed. São Paulo: Campus, 2006.

MENDOLA, M. Agricultural technology adoption and poverty reduction: A propensity-score matching analysis for rural Bangladesh. Food Policy, v 32, n.3, p.372-393, 2007.

MINTEN, B. e BARRETT, C. B. Agricultural Technology, Productivity, and Poverty in Madagascar. World Development, v. 36, n. 5, p. 797-822, 2008.

MINISTÉRIO DA SAÚDE. Diretrizes para atenção integral à saúde do trabalhador de complexidade diferenciada: protocolo de atenção à saúde dos trabalhadores expostos a defensivos agrícolas. Brasília, agosto de 2006.

NASCIMENTO, C. A. M. Em busca da Eco-eficiência. REAd-Revista Eletrônica de Administração, v. 6. n. 3, 2000.

OERLEMANS, N. e ASSOULINE, G. Enhancing farmers' networking strategies for sustainable development. Journal of Cleaner Production, v. 12, n. 5, p. 469-478, 2004.

ORGANIZAÇÃO PAN AMERICANA DA SAÚDE E ORGANIZAÇÃO MUNDIAL DA SAÚDE - OPAS/ OMS. Manual de vigilância da saúde de populações expostas a defensivos agrícolas. Brasília: OPAS/OMS, 1996.

QIZILBASH, M. Sustainable development: Concepts and rankings. The Journal of Development Studies, v. 37, n. 3, p. 134-145, 2001.

SACHS, I. Estratégias de transição para o século XXI: desenvolvimento e meio ambiente. São Paulo: Studio Nobel, 1993.

SAMARA, B. S. e BARROS, J. C. Pesquisa de Marketing: conceitos e metodologia. 3. ed. São Paulo: Prentice Hall, 2002.

SHARMA, S. e HENRIQUES, I. Stakeholder influences on sustainability practices innyhe canadian forest products industry. Strategic Management Journal, v. 26, p. 159-180, 2005.

SHI, T. e GILL, R. Developing effective policies for the sustainable development of ecological agriculture in China: the case study of Jinshan County with a systems dynamics model. Ecological Economics, v. 53, n. 2, p. 223-246, 2005.

SOARES, I. G. e IVAN, C. Econometria aplicada com o uso do EVIEWS. Fortaleza: UFC/CAEN, 2003.

TABACHINICK, B. e FIDELL, L. S. Using multivariate statistics. 3. ed. Chicago: Addison Wesley, 2003. 
UNNIKRISHNAN, S. e HEGDE, D. S. Environmental training and cleaner production in Indian industry: A micro-level study. Resources, Conservation and Recycling, v. 50, n. 4, p. 437-441, 2007.

$\mathrm{XU}, \mathrm{X}$. et al. Zoning of sustainable agricultural development in China. Agricultural Systems, v. 87, n. 1, p. 38-62, 2006.

WEI, J., XIAO, D. e ZENG, H. Sustainable development of an agricultural system under ecological restoration based on Emergy analysis:
A case study in northeastern China. International Journal of Sustainable Development and World Ecology, v. 15, n. 2, p. 103-112, 2008.

WOOLDRIGGE, J. M. Introdução à econometria: uma abordagem moderna. São Paulo: Pioneira Thompson Learning, 2006.

WOLF, S. A. Professionalization of agriculture and distributed innovation for multifunctional landscapes and territorial development. Agricultural Human Values, n. 25, p. 203-207, 2008. 